\title{
ESTUDIO DE DAÑOS Y CONTAMINACION ATMOSFERICA EN LOS MONUMENTOS HISTORICOS DE LA CIUDAD DE AREQUIPA, PERÚ
}

\author{
Viscarra Gonzales Ríos* \\ Pablo De La Vera Cruz \\ Chávez** \\ Rivalino Guzman Ale*** \\ Henry S. Lavalle Sullasi**** \\ Fredy Manuel Mayhua \\ Choque*****
}

Virginia Nelly. Chambi

Laura*****
RESUMO: A cidade de Arequipa, Peru, na sua historia sofreu processos cíclicos de destruição e reconstrução. Apos cada catástrofe foram acrescentadas novas tendências estilísticas. O movimento sísmico de 1784 demarcou o atual perfil técnico construtivo daquela cidade. Segundo o plano de gestão do Centro Histórico de Arequipa, feito pela Municipalidade Provincial de Arequipa no ano 2002, o 48,75\% das edificações são de sillar e o resto de outros materiais construtivos. Eis a importância deste estudo, na caracterização das patologias presentes nas edificações a base de sillar. Neste trabalho se apresentam as patologias observadas e, em paralelo, foi realizado o estudo da densidade veicular no centro histórico de Arequipa. Os resultados mostram uma forte correlação entre a densidade veicular e o número de patologias observadas. Este estudo permitiu definir três áreas com alto, mediano e baixo grau de contaminação, bem como definir os danos aos monumentos, produto das diferentes patologias e finalmente é importante destacar que as emissões geradas pelos veículos afetam os Monumentos Históricos, por tanto é necessário a implementação de medidas priorizadas para esta cidade.

Palavras-chaves: Patologias, Arequipa, Danos, Contaminação Atmosférica, Tráfego veicular.

ABSTRACT: In its history, the city of Arequipa, Peru, has undergone cyclical processes of destruction and reconstruction. After each catastrophe, new stylistic trends were added. The 1784 seismic movement delimited the current constructive technical profile of the city. According to the Historic Center of Arequipa management plan, created in 2002 by the Provincial Municipality of Arequipa, $48.75 \%$ of the buildings are of sillar and the rest of other building materials. Here is the significance of this study, in the characterization of the pathologies present in the sillar-based buildings. In this work the observed pathologies are presented and, in parallel, a study of the vehicle density in the Historic Center of Arequipa was carried out. The results show a strong correlation between the vehicle density and the number of pathologies observed. This study allowed to define three areas with high, medium and low degree of contamination, as well as to define the damages to the monuments, product of the different pathologies and finally it is important to emphasize that the vehicles-generated emissions affect Historical Monuments, therefore it is necessary the implementation of priority measures to the city.

Keywords: Pathologie, Arequipa, Damage, Atmospheric contamination, Vehicular traffic. 


\section{Introducción}

En los últimos años pudo ser observado un interés creciente por el patrimonio histórico, lo cual se plasmo de diversas formas, desde los planes de salvaguarda, recuperación de obras y numerosos proyectos de restauración. Según Morales, el patrimonio puede ser entendido como un signo de identidad de los pueblos en sus diferentes expresiones como el territorio, la flora y la fauna, creaciones y expresiones de personas que la han habitado, las instituciones sociales, legales y religiosas, el lenguaje y la cultura material através de la historia (Morales, 1996).

Por otro lado, la contaminación es tan antigua cuanto el ser humano, y es el resultado de sus actividades económicas y sociales; su consecuencia es el cambio en las propiedades del medio ambiente, en perjuicio de animales, plantas, materiales y, en última instancia, del mismo ser humano. Los materiales sufren daños de muchas maneras, por ejemplo, la corrosión en los metales, deterioros en el hule y el vidrio, desmoronamiento y erosión en materiales de construcción y destrucción en obras de arte. Los efectos adversos de la contaminación atmosférica pueden ser observados en edificios históricos y pueden mitigarse manteniendo la superficie que esté limpia, aunque la única solución permanente de este problema es eliminarla contaminación (Uruchurtu 2008).

Los edificios, monumentos y estatuas expuestos al aire libre actúan como reservatorios de compuestos químicos atmosféricos, la mezcla de estos compuestos y el agua pueden generar por diversos caminos la formación de daños como la presencia de eflorescencias, patinas o costras negras en las cuales los aerosoles, las esporas, el polvo y toda clase de materia particulada se encuentra atrapada por la matriz mineral (Uruchurtu 2008).

La ciudad de Arequipa, localizada en la provincia de Arequipa, desde la cual se observan una serie de conos volcánicos que forman nevados como el Misti, Chachani y Pichu Pichu, dentro de esta encontramos el centro histórico que representa la respuesta integrada de manos nativas y las técnicas y características de construcción con diseños europeos, expresadas en el admirable trabajo de los maestros coloniales y los albañiles nativos. Esta combinación de influencias, y la respuesta a un terreno inestable debido a los terremotos, está ilustrada por muros robustos, arcos, pórticos, bóvedas, patios y espacios abiertos, y una fuerte influencia indígena en la intrincada decoración barroca de sus fachadas (Municipalidad de Arequipa, 1999). 
Esta ciudad fue fundada el 15 de agosto de 1540, bajo la denominación de "Villa Hermosa de Nuestra Señora de la Asunta" en nombre del marqués don Francisco Pizarro y el 22 de setiembre de 1541 el monarca Carlos V en Cédula Real ordena que se le llamé "Ciudad de Arequipa". En el periodo virreinal ya mostro importancia, misma que fue reconocida por la Corona Española a través de los títulos que se le conceden tales como "Muy Noble y Muy Leal" y el de "Fidelísima". En la historia republicana del Perú el protagonismo de la ciudad de Arequipa fue gravitante, pues llegó a ser declarada "Capital de la República" durante el gobierno de Lizardo Montero. Fue declarado por la Unesco como "Patrimonio Cultural de la Humanidad", entre otros motivos por ser la única ciudad en el mundo en donde se utiliza el sillar para la arquitectura. (Gonzales Y Huarachi, 2000)

El sillar es el principal material de construcción de la arquitectura arequipeña tradicional, que se manifiesta en casonas, iglesias, portales, piletas, cúpulas entre otras que son la representación más auténtica de una arquitectura de origen volcánico. Los constituyentes químicos del sillar son de naturaleza vítrea, cristalina y lítica: feldespato potásicos, oligoclasa, cuarzo, vidrio, biótica y óxido de hierro; con materias accesorias como piedra pómez, andesitas y escorias lapilliticas su textura es porosa y absorbe líquidos sin perder cohesión, resiste el calor a más de $500^{\circ} \mathrm{C}$, es mal conductor de la temperatura y puede ser encontrado en los colores blanco, rosado y crema (Gonzales, 2014).

Considerando todos estos hechos, es que, este trabajo tiene como objetivo estimar el grado de contaminación, a partir de un levantamiento vehicular por hora punta, y asociar estos resultados con las patologías observadas en los monumentos arquitectónicos del Centro Histórico de la ciudad de Arequipa.

\section{Marco Teorico}

Según el plan de gestión del Centro Histórico de Arequipa elaborado por la Municipalidad Provincial de Arequipa en el año 2002, el 48.75\% de edificaciones sonde sillar, siendo el resto de material estales como: ladrillo y concreto, y un menor número de calamina, madera y otros materiales. Ya considerando las edificaciones patrimonial aun no declaradas pero con potencial para serlo, casi el $100 \%$ de ellas son de material sillar, pues hay que recordar que este material fue utilizado de forma masiva en nuestra ciudad hasta finales del siglo XIX (Conam, 2006), por este motivo se hace necesario una breve descripción de este elemento constructivo típico de la ciudad. 


\section{El Sillar}

Son depósitos de flujo piroclástico endurecido de composición dacítica y riolítica con una edad de mitad del Mioceno y luego Plioceno, se extiende alrededor de $600 \mathrm{~km}^{2}$ del Cuaternario de estrato de los volcanes de Chachani y Misti llenando las depresiones de Arequipa, con un espesor de 100 a $200 \mathrm{~m}$ en el cañón del Chili y rió Yura. El sillar es parte de un tufo volcánico fragmentario de origen piroclástico, de aspecto masivo, cuya coloración comprende diferentes tonos que van desde el gris hasta el blanco (Gonzales e Huarachi, 2000).

La denominación como "sillar" solo es de carácter local en Arequipa, siendo técnicamente conocidos como tufos piroclásticos (cenizas y lapillis) también como tobas volcánicas y/o ignimbritas (William y Goldich, 1956).

Según manifiesta el arquitecto Ramón Gutiérrez (1992), la primera tecnología arequipeña para la edificación de inmuebles debió ser la piedra "rodada" o el "canto", extraídas del río Chili y de las torrenteras para formar los muros de "cal y canto", pero de la misma forma da cuenta de la tempranísima utilización de "cantería blanca", para la realización de la portada de la iglesia matriz por el maestro cantero Toribio de Alcaráz en el año de 1544. Primero en portadas, luego en elementos de soporte y hasta en coberturas en forma de bóvedas, el sillar se fue convirtiendo en el material por antonomasia de la ciudad de Arequipa. En un primer término en la arquitectura religiosa y una vez dominada la técnica ya barata do los costos en viviendas ricas y pobres de la ciudad y de la periferia, este material se convirtió en el exclusivo hasta finales del siglo XIX, y a comienzos del XX es utilizado vivamente para el tradicional muro de carga o como unidad de albañilería para los recientes sistemas constructivos "modernos".

Es así que el sillar va adquiriendo connotaciones no solamente funcionales y técnicas sino también simbólicas y hasta místicas, siendo reflejo del poblador y de la ciudad de Arequipa (Neira et. al. 1990).

\section{Principales Agentes y Mecanismos de Alteración en Monumentos Historicos}

Los agentes que contribuyen en mayor o menor medida a la alteración de los elementos pétreos de los monumentos y a la aparición de las formas de deterioro son: el agua, los contaminantes atmosféricos, las sales solubles y los organismos vivos (Alcalde et. al., 1990). A pesar que el presente trabajo pretende abordar el tema de los contaminantes atmosféricos, no se puede ser ajenos a los demás agentes de alteración pues en muchos casos éstos interactúan 
conjuntamente para acelerar los procesos de deterioro antes descritos, por ello seran abordados y analizados en su conjunto:

El Agua

Según Cabrera Garrido (1979), el agua, en sus distintos estados o fases, es el más importante agente de alteración. Es un agente polivalente dados los cambios de fase que puede experimentar. Actúa también como vehículo de transporte de otras sustancias como las sales solubles, los organismos vivos y los contaminantes atmosféricos de los cuales seran tratados con mayor detenimiento. La humedad del sillar en las edificaciones procede principalmente de tres fuentes:

- De la Atmósfera, llamada condensación, que para el caso de la ciudad de Arequipa, ésta no resulta tan relevante dado el porcentaje de humedad relativa media de $46 \%$, dato adquirido del SENAMHI.

- De las Aguas de lluvia, por absorción, presente sobre todo durante los meses de Diciembre, Enero, Febrero y Marzo, pues es la época de lluvias que según el año y dependiendo de factores como la presencia del fenómeno del niño, se presentan en mayor o menor grado.

- Del Suelo y Subsuelo, por capilaridad, siendo este el principal factor de humedad en las edificaciones de la ciudad, puesto que existe toda una red de canales de épocas pretéritas que subsisten en el subsuelo, además de sistemas de agua y desagüe colapsados que no sólo afectan a las edificaciones a las que pertenecen sino también a las edificaciones vecinas.

El contenido de humedad de una piedra está regulado por su capacidad de absorción y de evaporación. En el seno de las piedras porosas, como es el caso del sillar, el agua se distribuye en función de distintos niveles de imbibición, los cuales están estrechamente relacionados a su estructura porosa. Su acción se manifiesta a través de diversas reacciones químicas con el sustrato pétreo (disolución, hidrólisis, hidratación, oxidación-reducción etc). La disolución afecta mayoritariamente a piedras de naturaleza carbonatada, lo cual no se profundizará en este trabajo puesto que en Arequipa no existe este material constructivo.

En construcciones de calizas o mármoles, sin embargo si es necesario resaltar la reaccion de hidrólisis pues estas afectan fundamentalmente a componentes silicatados como, por ejemplo, feldespatos presentes en el sillar. La hidrólisis conduce, en última instancia, a la formación de minerales arcillosos así, por ejemplo, el feldespato potásico se convierte en caolinita. La 
hidratación consiste en la incorporación de moléculas de agua por parte de un mineral. Este sería el caso del sulfato cálcico cuando se transforma en yeso.

\section{Las Sales Solubles}

La presencia de sales solubles en las edificaciones de valor patrimonial de la ciudad de Arequipa es de consideración pues esta se aprecia a simple vista en varias de las construcciones analizadas. Estas sales ocasionan daños físicos y químicos en el sillar cuando se cristalizan en su interior o en la superficie. Sin embargo su grado de nocividad es variable y depende no solo de las características de la sal, sino también de las condiciones ambientales, como variaciones de humedad, temperatura etc. (Cabrera Garrido 1979).

La procedencia de las sales en los sillares de los monumentos es diversa, lo más frecuente es que provengan de fuentes externas: suelos, morteros, metabolismo de organismos, anteriores construcciones etc. Las sales solubles más frecuentes son los sulfatos, seguido de los cloruros, carbonatos y nitratos (Prada et al, 1995).

Según Prada (1995), el deterioro producido por las sales solubles puede llevarse a cabo a través de varios mecanismos, siendo los más generalizados la cristalización y la hidratación. En el primer caso, los daños se producen cuando las tensiones locales generadas por el empuje del cristal al crecer en el interior de un poro o microfisura sobrepasa la resistencia a la tracción de la roca. En el segundo caso, el paso de la sal anhidra a la hidratada comporta asimismo presiones en las paredes de los poros, las cuales pueden provocar fenómenos disruptivos.

\section{Organismos Vivos}

No siempre la presencia de organismos vivos supone necesariamente un daño a la piedra, pues a veces la alteración es simplemente estética. Entre los agentes bióticos de mayor incidencia destacan: Bacterias, hongos, algas, líquenes, briofitas, plantas superiores y animales (Del Monte 1990). En la ciudad de Arequipa el bio deterioro resulta puntual en ciertos edificios ya que las condiciones climáticas no generan un caldo de cultivo propicio para su formación, sin embargo un estudio más profundo al respecto es recomendable.

\section{Contaminantes atmosféricos}

Este agente de alteración es considerado el centro de este estudio ya que en la ciudad, dados los altos índices de contaminación, el deterioro de los sillares que componen los monumentos es evidente. 
Los contaminantes atmosféricos tanto sólidos, como líquidos y gaseosos reaccionan con los componentes de la piedra, dando lugar a diversas formas de alteración ya la degradación del material (Prada et al, 1995).

La mayoría de contaminantes presentes en el aire provienen de fuentes antropogénicas, para ser exactos de la combustión de combustibles fósiles provenientes de nuestro parque automotor en un $76 \%$, el $19 \%$ por el sector industrial y el $5 \%$ por emisiones comerciales (Digesa, 2005).

Entre los principales tipos de contaminantes que influyen directa e indirectamente en el deterioro de los materiales pétreos y en los morteros se tiene: compuestos de azufre y de nitrógeno; óxidos de carbono, cloruros y fluoruros; compuestos orgánicos volátiles y partículas sólidas.

Según la Dirección General de Salud Ambienta (Digesa), en la cuenca atmosférica de Arequipa los contaminantes identificados fueron: monóxido de carbono, dióxido de azufre, óxidos de nitrógeno, partículas totales en suspensión (PTS), y compuestos orgánicos volátiles (COV). El contaminante mayormente emitido son los PTS seguidos de dióxido de azufre, Las mayores emisiones de CO y COV son producto de la combustión de la gasolina en automóviles (Digesa, 2015).

\section{- Compuestos de azufre}

Como ya se ha hecho mención en la cuenca atmosférica de la ciudad de Arequipa se ha encontrado cantidades considerables de $\mathrm{SO}_{2}$, lo suficientemente elevado como para ser considerado uno de los factores más negativos respecto a la alteración de la ignimbrita y los morteros, porque una vez en el aire el $\mathrm{SO}_{2}$ se oxida rápidamente a $\mathrm{SO}_{3}$, y en combinación con la humedad del ambiente, da lugar a la aparición de sulfatos dañinos para la piedra.

La formación de sulfatos comporta un notable incremento de volumen, creando costras sulfatadas y favoreciendo las descamaciones, desplacaciones y otras formas de deterioro, favoreciendo también la alteración de los silicatos (Alonzo y Martinez 2003).

La acción del $\mathrm{SO}_{2}$ en la piedra se puede realizar a través de dos vías principales seca y húmeda; mecanismos que fueron descritos por Garlan (1978). En el caso de la deposición seca el $\mathrm{SO}_{2}$ alcanza la superficie de la piedra en forma gaseosa. En contacto con el carbonato cálcico reacciona dando lugar a sulfito cálcico, el cual en presencia del agua y de catalizadores se convierte en sulfato conforme se observa en la Figura 1. 
En la deposición húmeda la oxidación del $\mathrm{SO}_{2}$ tiene lugar en la atmósfera (disolviéndola en las gotas de agua de nubes y niebla), o bien en la misma superficie del sillar (durante la condensación de vapor de agua) en ambos casos el ataque al sillar se realiza a través del ácido sulfúrico diluido, conforme se observa en la Figura 2.

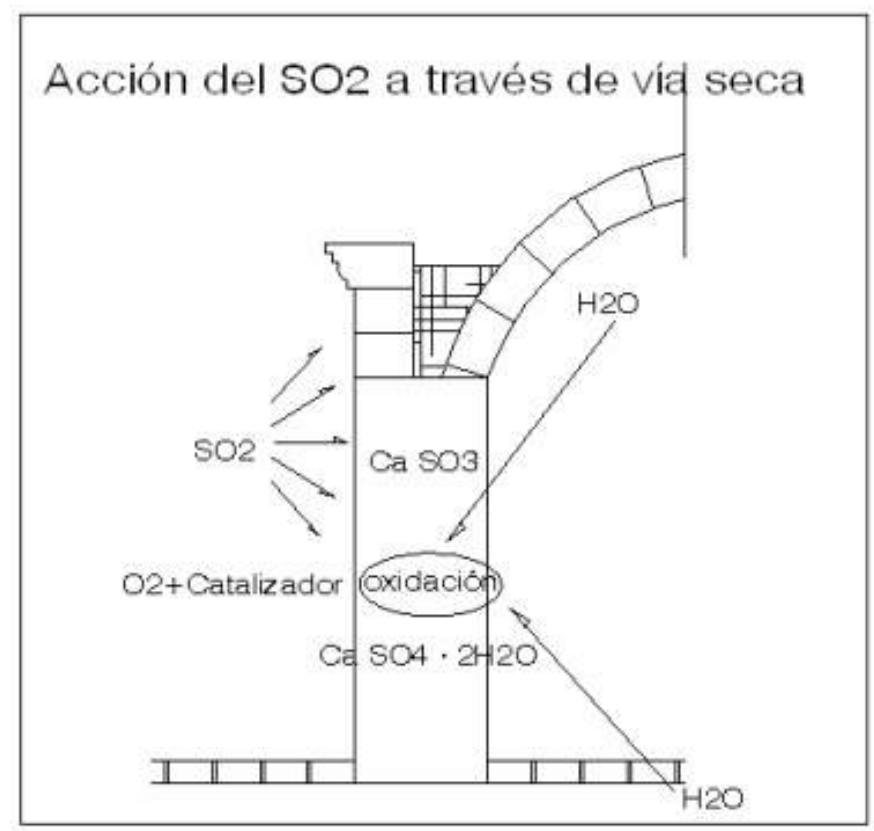

Figura 1: Proceso de deposición y absorción del SO2 a través de via seca. Fuente: Los autores.

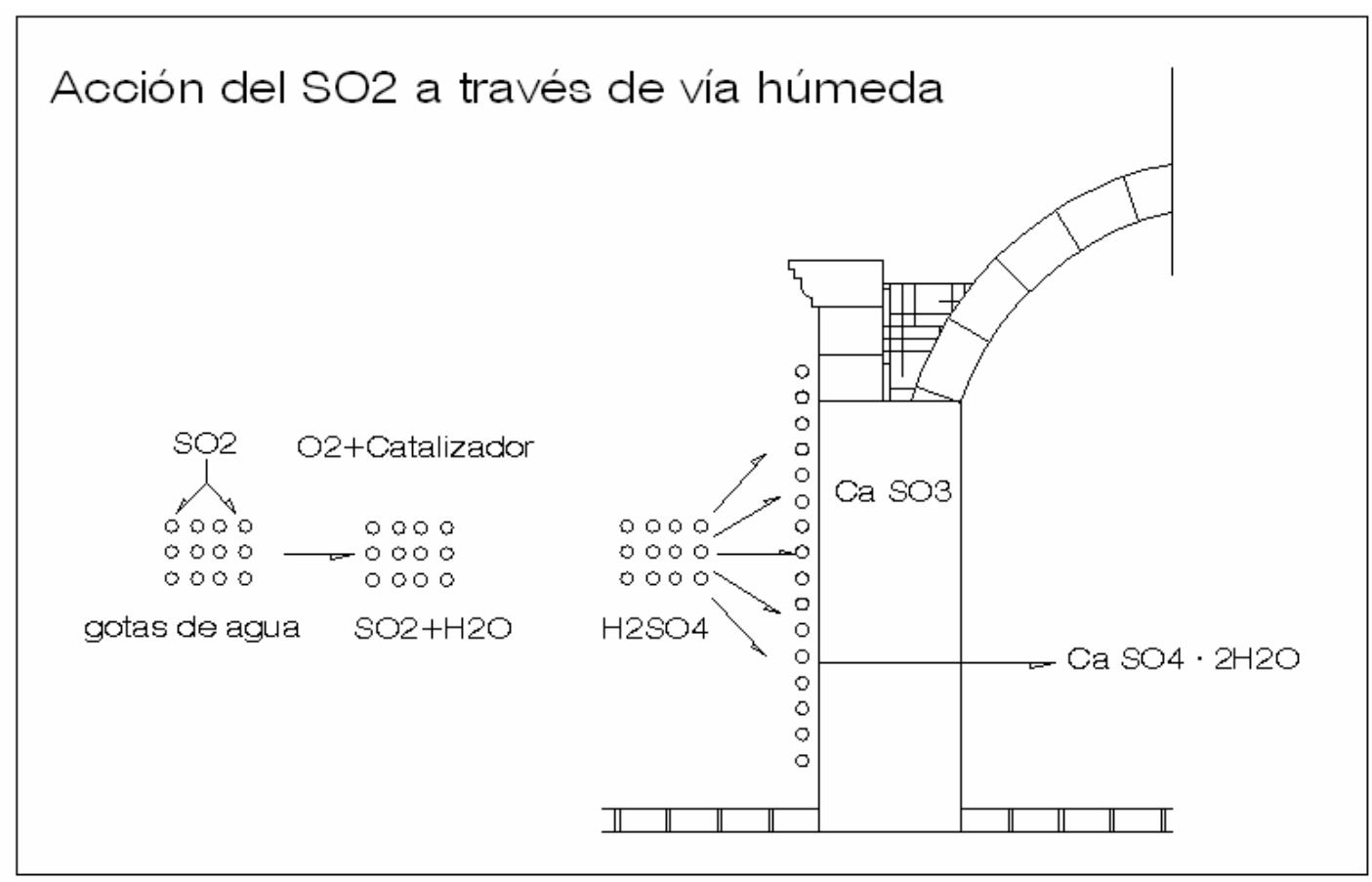

Figura 2: Proceso de deposición y absorción del SO2 a través de via húmeda. Fuente: Los autores. 


\section{Compuestos de nitrógeno}

Los principales son los óxidos que para el caso de Arequipa estos son producidos por los automóviles. El mayor problema para las edificaciones de valor patrimonial reside en la conversión fotoquímica de los NOx en ácido nítrico. Un efecto adicional de los óxidos de nitrógeno es su papel como catalizadores del a reacción: $\mathrm{SO}_{2}$ para $\mathrm{SO}_{3}$ (Vassilako y Salta,1993).

\section{-Óxidos de Carbono}

El dióxido de carbono es un componente natural de la atmósfera, pero en las últimas décadas éste ha crecido sensiblemente, sobre todo en áreas urbanas, como es el caso de Arequipa, debido fundamentalmente a la quema de combustibles fósiles (Prada et al, 1995).

El CO en principio no presenta de por si un grave problema para el sillar, perola dificultad reside en que este se oxida normalmente a $\mathrm{CO}_{2}$, actuando también como catalizador en las reacciones de oxidación del $\mathrm{SO}_{2}$ (Prada et al, 1995).

\section{- Compuestos orgánicos volátiles}

Se ha determinado que los compuestos orgánicos volátiles (COV) se encuentran dentro de la cuenca atmosférica de Arequipa, dentro de ésta categoría se encuentran los hidrocarburos de diferentes tipos y como sucede en los otros casos estos provienen, mayoritariamente, del parque automotor de la ciudad de Arequipa (Digesa, 2015).

Se puede comprobar a simple vista que los COV contribuyen sustancialmente al enmugrecimiento de las fachadas, modificando el aspecto blanco de las edificaciones de sillar, además de ser actores para la formación de costras y pátinas negras.

\section{-Partículas Totales en Suspensión}

Según datos de la Digesa (2015), el mayor contaminante atmosférico son las PTS, dentro de estas partículas sólidas se puede encontrar: polvo, hollín, cenizas volantes etc. En diferentes concentraciones, su composición es muy variable al igual que sus formas, teniendo la particularidad que estas se asientan con mucha facilidad en la superficie de las construcciones de sillar colaborando activamente al ensuciamiento de las mismas.

Además de ello debido a su gran superficie específica, tienden a aumentar la humedad de las piedras, absorbiendo el vapor de agua de la atmósfera y facilitando las reacciones entre el sillar y los contaminantes (Prada, 1995). 


\section{Las Patologías}

Las "patologías" son los procesos de transformación o cambios que suceden en los monumentos o de los elementos que los componen; y que ocasionan su deterioro (Rodriguez, 2004).

Son las enfermedades que afectan los monumentos, ellas tienen condición dinámica, es decir que no dejan de actuar mientras no cese la acción de los diferentes agentes que la causan. Además originan cambios irreversibles en los monumentos por su condición de no ser entes vivos, los que se conocen como daños (Rodriguez, 2004; Petrucci, 1972; Helene 1992).

Los "agentes" son las condiciones que propician el desarrollo de cambios en la composición, estructura y morfología de los elementos afectados. Estos pueden ser de diferente naturaleza y no solo actúan independientemente sino que principalmente se conjugan para dar origen a las diferentes patologías (Petrucci, 1972).

Los "daños" son los resultados de un proceso patológico. Destruyen un elemento, una parte o del monumento en su conjunto. Estos están asociados a condiciones diferentes a la naturaleza de la patología misma por ejemplo la gravedad o las fuerzas que actúan en un desplome (Isaias, 2011). Además con llevan a la pérdida de los valores de los monumentos, como por ejemplo su "carácter" $y$ " autenticidad" (Brandi, 1977).

Las Patologías conllevan a intervenciones en diferentes grados sobre los monumentos, desde los más leves hasta los más radicales; y la eficacia de estos depende de la calidad científica de las intervenciones, especialmente de la identificación de las patologías.

\section{Metodologia}

\section{Objeto de Estudio}

Nuestro objeto de estudio esel perímetro definido por el Instituto Nacional de Cultura (INC) como "Zona Monumental de Arequipa", declarada por Resolución Suprema 2900-72-ED, del 28 de Diciembre de 1972 (212.70Has.), que contienen aproximadamente 2650 inmuebles, de los cuales 314 son monumentos expresamente declarados como patrimonio nacional, y existe más de 200 con el potencial y cualidades suficientes como para ser incluidos también en esta categoría. 
Se debe aclarar que este perímetro monumental tiene un área mayor a la reconocida por la Unesco como "Patrimonio Cultural de la Humanidad", la cual se circunscribe a donde hay una mayor concentración de monumentos históricos expresamente declarados, esta diferencia puede ser observada en la Figura 3.

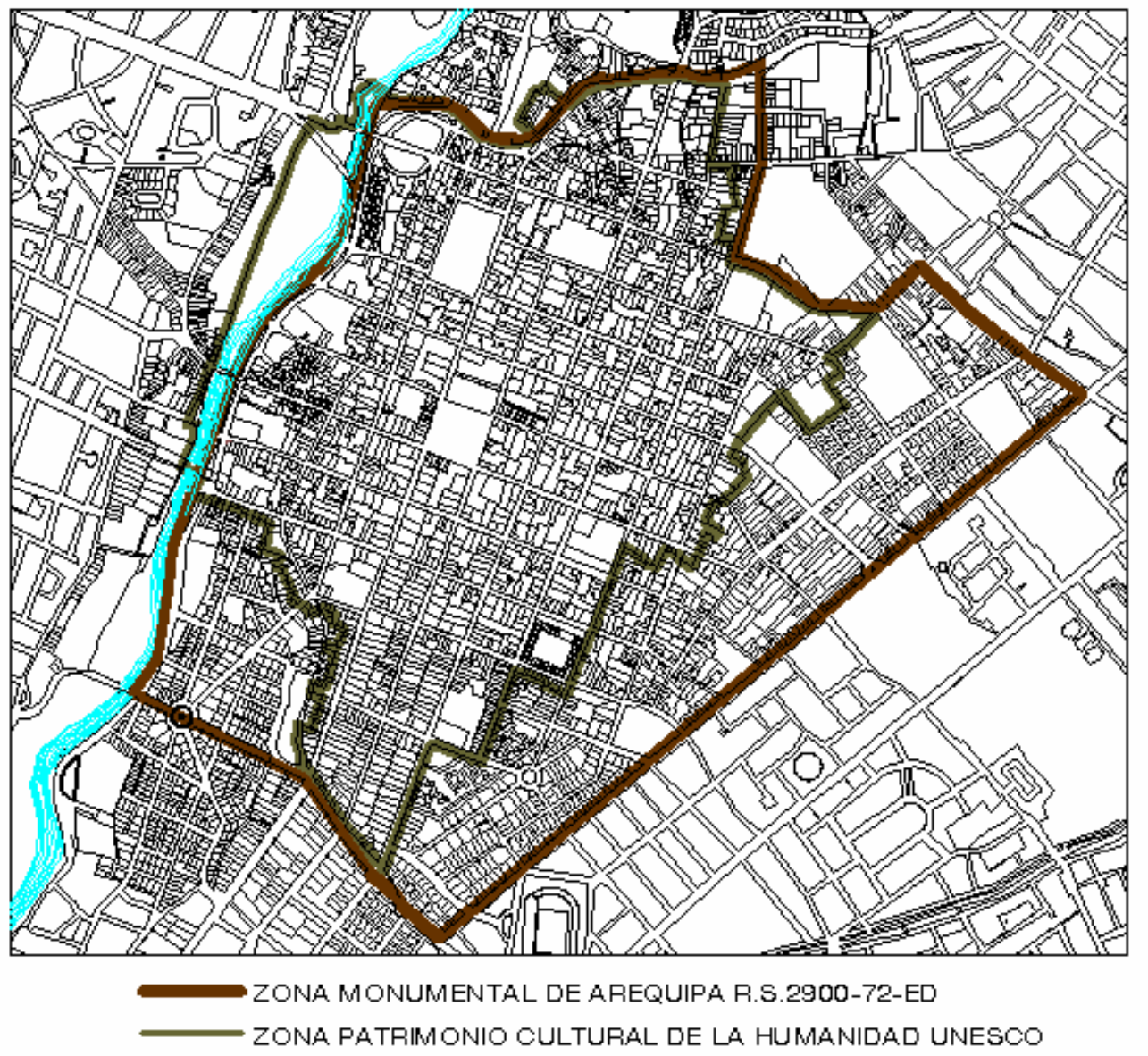

Figura 3, Mapa del perímetro del centro histórico según la Unesco y según el plan de Gestión del Centro Histórico de la provincia de Arequipa.Fuente: Adaptado de Municipalidad Provincial de Arequipa, 2017.

Según datos del INC, los monumentos históricos se dividen de la siguiente manera:

Tabla 1. División de los monumentos encontrados en el centro histórico de Arequipa por tipo de monumento. Fuente: INC, 1999.

\begin{tabular}{ccc}
\hline TIPO DE MONUMENTO & № & $\%$ \\
\hline Monumentos Religiosos & 23 & 7.3 \\
\hline Monumentos Civil Público & 21 & 6.6 \\
\hline Monumentos Militares & 2 & 0.7 \\
\hline Monumentos Civil Doméstica & 269 & 85.4 \\
\hline TOTAL & 315 & 100 \\
\hline
\end{tabular}




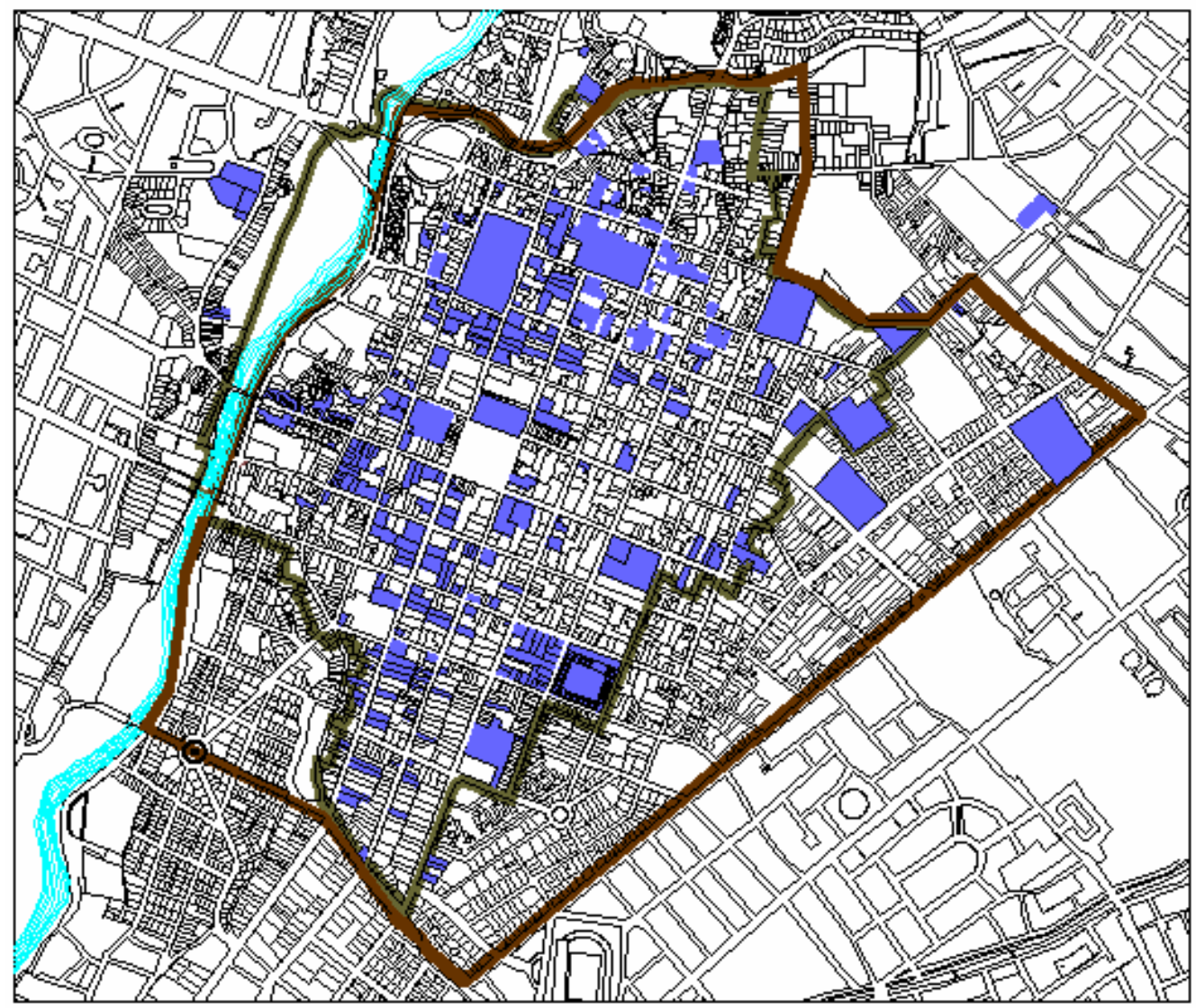

MONUMENTOS REPRESENTATIVOS DE LA, ARQUITECTURA: CVIL, DOMÉSTICA PÚBLICA Y RELIGIOSA EXPRESAMENTE DECLARADOS

Figura 4. Mapa del centro histórico de Arequipa mostrando los monumentos de arquitectura civil, domestica pública e religiosa.Fuente: Adaptado de Municipalidad Provincial de Arequipa, 2017.

La Figura 4 muestra la distribución de los monumentos representativos de la arquitectura arequipeña. Considerando la gran cantidad de monumentos observados, nuestro estudio será realizado por calles. A seguir una breve descripción de los monumento históricos que fueron encontrados en las calles e/o vías de este estudio, a partir de la obra "Relación de Monumentos históricos del Perú" del Instituto Nacional de Cultura (INC, 1999).

Calle Puente Grau: Es considerada Ambiente Urbano Monumental y tiene dentro de sus características principales ser el límite norte del antiguo Damero Fundacional, por lo que toca tangencialmente también el antiguo Barrio de San Lázaro, el cual remonta su trazado hasta épocas prehispánicas. Dentro de los principales Monumentos Edilicios con los que limita si tiene el costado Norte del complejo edificatorio de la Orden Franciscana, así como el antiguo Colegio de la Educandas, posterior Cárcel de Mujeres y actual complejo artesanal denominado "Fundo del Fierro". Al ser una calle límite, las edificaciones del frente pertenecen ya a una época Republicana, pero no por ello de menor valor patrimonial que las coloniales. 
Calle La Merced: La Calle La Merced es una de las que posee más alto valor patrimonial, dado el gran porcentaje de edificaciones que son Monumentos Históricos expresamente declarados y de los potencialmente a serlo. Esta calle presenta variados estilos de los siglos XIX y XX, entre los que se puede mencionar Neoclásicos, y eclécticos con marcada influencia Europea. Dentro de las edificaciones más conocidas se puede mencionar: a la Casona Goyeneche, actual banco de la Nación, La Casona museo "Santuarios Andinos" de la UCSM, La Casa del Corregidor etc. Y obviamente el complejo arquitectónico que da nombre a toda la Calle, La Iglesia y Claustros de la Orden Mercedaria.

Vías Perimetrales a la Plaza de Armas: Estas vías circundan a los denominados portales y a la Basílica Catedral, poseen gran valor patrimonial, pues son el reflejo simbólico y centro geométrico de la ciudad patrimonial. Si bien los portales que se observan actualmente pertenecen en su concepción y diseño a la segunda mitad del siglo $X X$, estos pertenecen ya indiscutiblemente al imaginario colectivo de la sociedad arequipeña y son justificadamente declarados como patrimonio monumental. De la misma forma La Basílica Catedral, con la imagen neoclásica producto de la intervención del XIX del arquitecto Lucas Poblete, es uno de los monumentos más representativos que posee la ciudad de Arequipa, pero además de estas estructuras reconocibles y simbólicas existen otras edificaciones con alto grado de valor patrimonial, que por haber quedado ocultas tras los portales actuales son poco conocidas por la población, siendo el caso mas resaltante la denominada "Casa del Coronel Flores del Campo "ubicada en el denominado "Portal de Flores". Hay que hacer mención también al valor patrimonial de la pileta central de la Plaza de Armas, que por su material no hace parte del presente estudio.

Calle Palacio Viejo: La Calle Palacio Viejo ha sido declarada también como "Ambiente Urbano Monumental, por resolución 2900-72- ED, del 28-12-06, debiendo destacarse en esta calle la cuadra que está limitada por las vías de Sucre y Cruz Verde, en la cual se puede apreciar que la mayoría de inmuebles del norte de la vía son monumentos históricos con declaración expresa. Entre los monumentos más importantes de esta Calle se tiene a la Capilla del Sagrado Corazón, de marcada influencia Neogótica, además de la fachada lateral del palacio de los Goyeneche.

Calle San Camilo/Consuelo: La Calle San Camilo, lleva su nombre por ser el sector en donde se encontraba la Iglesia y el hospicio de la Orden de los Padres Agonizantes de San Camilo, o más conocidos en su época como la comunidad de la buena Muerte, este templo construido en el año de 1802 quedó muy seriamente afectado luego del sismo de 1868 y dado el escaso 
número de religiosos de la orden la comunidad, quedó suprimida fue por ello que este bello templo de estilo neoclásico es demolido en su totalidad para que años más tarde el solar fuera destinado para la construcción del mercado de la ciudad el cual se empezaría a edificar en el año de 1884. Este bello edificio ha sufrido una serie de modificaciones en su estructura formal y funcional, pero mantiene todavía algunos elementos dignos de preservar, como su cobertura y los elementos que la soportan, valiendo ello para que sea reconocido como Monumento Representativo de la Arquitectura Civil de la ciudad. Esta edificación es pues el punto neurálgico de la Calle, habiendo también una gran cantidad de edificaciones monumentales, entre las calles Piérola y San Juan de Dios, que pertenecen a la denominada Arquitectura doméstica de la ciudad.

Calle Cruz Verde / Villalba: La Calle Cruz Verde con su prolongación a la Calle Villalba fue el perímetro del damero fundacional original de 49 manzanas, es por ello que la tipología arquitectónica de las edificaciones que configuran estas dos calles es el de una arquitectura de "límite" asemejando a las murallas que no tuvo la ciudad, pudiéndose encontrar edificaciones de la importancia de la denominada "casa de la Moneda" que con sus gruesos y altos muros de apariencia masiva y estereotomía perfecta marcaban el límite de la ciudad con el medio natural de la época.

Avenida Goyeneche: Esta avenida lleva este nombre por ser el sector en donde se ubica el Hospital del mismo nombre, el cual fue diseñado y edificado en la primera década del siglo XX, en los terrenos pertenecientes a la acaudalada familia Goyeneche. Esta edificación de marcado estilo neogótico, diseño del ingeniero arquitecto Pedro Paulet, vino a reemplazar al ya caduco hospital de San Juan de Dios y vitalizó un naciente sector de la ciudad perimetral a la zona en ese entonces consolidada.

Pese a que el hospital sufrió serias transformaciones y demoliciones, sobre todo después de los sismos de 1958 y 1960, conserva todavía los valores suficientes para ser considerado como uno de los principales monumentos representativos de la arquitectura civil pública de la ciudad, además de ello la avenida está enmarcada con una serie de construcciones propias, de la época del "ensanche" de la ciudad, con un estilo ecléctico e historicista las cuales son consideradas también como parte de la denominada "Zona Monumental" de la ciudad. Hay que resaltar también la presencia, en esta avenida, del orfanato "Chávez de la Rosa”, el cual está catalogado también como patrimonio nacional. 
Calle Santa Catalina: La Calle Santa Catalina, en cuanto a valores patrimoniales se refiere, es una de las de mayor valor en la ciudad, puesto que presenta una alta concentración de inmuebles que han sido declarados como patrimonio cultural representantes de la arquitectura arequipeña, pero su importancia reside también en albergar al monumento que la nomina, es decir el complejo religioso de las madres Dominicas de Santa Catalina de Siena. Este monasterio se empezó a edificar en el año de 1570, alberga entre sus muros un complejo arquitectónico que atestigua la evolución de la arquitectura de la ciudad a través de los siglos, y ha sido una razón de peso para que Arequipa sea declarada como "Patrimonio Cultural de la Humanidad".

Calle San Francisco: Esta calle lleva este nombre por se conducir directamente al complejo arquitectónico de la Orden Franciscana, el cual, emplazado en la Calle Zela, contiene la Iglesia y Claustros de la Orden, así como el parque del mismo nombre y el templo de la Tercera Orden Franciscana. Junto con las Calles Santa Catalina y La Merced es la que mayor número de monumentos arquitectónicos posee, siendo en su mayoría monumentos representativos de la Arquitectura Civil doméstica de la Ciudad, los cuales datan desde épocas coloniales hasta republicanas. Además de los monumentos de la vida doméstica, hay que destacar los pertenecientes a la arquitectura civil pública dentro de los que destacan los locales de la Prefectura Departamental, Subprefectura y antigua Corte de Justicia.

Calle San Agustín: En esta calle reside el complejo arquitectónico de la orden Agustina y en la Universidad del mismo nombre, siendo la iglesia, en cuanto a su portada se refiere, uno de los ejemplos más importantes del llamado estilo "Barroco mestizo" de la ciudad. Los Claustros, son hoy en día ocupados para las actividades educativas y culturales de la Universidad Nacional de San Agustín de Arequipa, siendo de su pertenencia también otro inmueble en el frente de este complejo, formando así un núcleo de carácter académico y cultural.

Calle Puente Bolognesi: Fue nominada de esta manera por el puente "Real" que conectaba a la ciudad con la otra margen del río Chili. Esta estructura fue realizada en el siglo XVII y mantiene vigente su uso. Además de esta importante y antigua estructura vial la calle se caracteriza por la presencia de los llamados "Tambos", los cuales eran lugar de aposento de los eventuales visitantes y comerciantes que venían a intercambiar sus productos a la ciudad. Hoy en día estas estructuras vienen siendo restauradas y mejoradas las condiciones de vida de sus habitantes, convirtiéndolas también en lugar turístico para los visitantes de la ciudad. 
Calle Zela: Esta calle es un importante ambiente Urbano Monumental de la ciudad, y confluye con la "Plaza de San Francisco" la cual posee un altísimo valor patrimonial y toca tangencialmente a la Iglesia de la Orden Franciscana, convento de los religiosos, y finalmente en el "Monasterio de Santa Catalina". En cuanto a las demás edificaciones, hay varias que poseen valor patrimonial.

Calle Ugarte: La Calle Ugarte, es una vía de la ciudad que ha ido sufriendo una serie de transformaciones a lo largo de la historia urbana de Arequipa, sin embargo guarda todavía una serie de edificaciones que le ha valido para que sea reconocida también como "Ambiente Urbano Monumental", tiene la particularidad de rematar visualmente en el mencionado "Monasterio de Santa Catalina de Siena", para posteriormente continuar hasta la bajada del río Chili, conducente al "Matadero"de la ciudad, este tramo tiene monumentos históricos expresamente declarados como representativos de la arquitectura doméstica de la ciudad, destacándose el local del Instituto Cultural Peruano Alemán.

Calle Álvarez Thomas: Esta contiene entre las estructuras edilicias que la configuran una gran cantidad de inmuebles declarados como monumentos históricos, al inicio de la calle, en la primera cuadra, se puede observar la portada lateral de la Iglesia de la Compañía denominada "Portada del Apóstol Santiago" que, por su antigüedad y valor histórico-artístico, es una de las más importantes de la ciudad. Además de ello se encuentra una serie de casonas de gran importancia representantes de la arquitectura doméstica en su mayoría utilizadas hoy en día como locales de uso comercial.

\section{Procedimientos Utilizados}

Para el levantamiento de la cantidad de vehículos en horas punta, en las diferentes calles y avenidas seleccionadas del centro histórico de Arequipa, fue realizado a través de contaje directo de los vehículos y registro de sus características, esto en días consecutivos.

Fue realizado un diagnóstico de las patologías observados en los monumentos históricos, en las calles y avenidas seleccionadas, que son causadas por la contaminación del ambiente. Para ello se ha seguido la metodología de selección de una muestra. Sobre esta muestra se ha procedido a la observación directa de las patologías existentes a simple vista, con uso de lupas y también por medio de fotografías de alta resolución (Figura 5). 


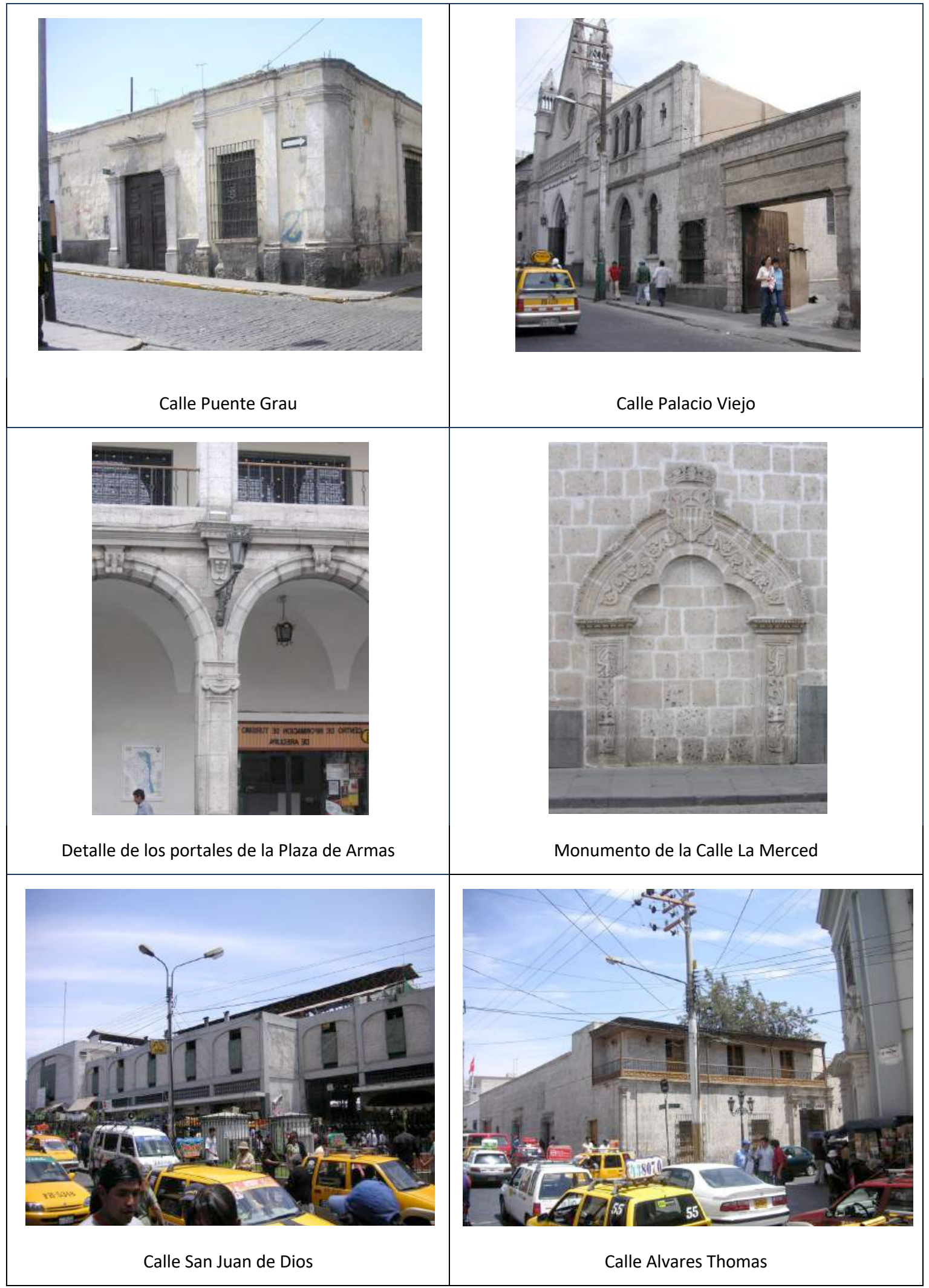

Figura 5: Principales calles del Centro Histórico de Arequipa.Fuente: Los autores. 


\section{Resultados}

A seguir es descrito el cuantitativo de vehículos observado en hora punta en los trechos con alto, mediano y bajo grado de contaminación. Seguidamente serán descritas las calles afectadas con un alto grado de contaminación vehicular.

Calle Puente Grau: Según lo observado es una de las que más alto grado de contaminación posee, registrándose un total de 1652 unidades vehiculares por hora punta, además de ello el tipo de vehículos que circulan por estas calles son las denominadas "combis" y "custer" que, por su escaso mantenimiento, despiden ingentes cantidades de contaminantes gaseosos, además de ello es alto también el número de taxis y vehículos particulares.

Calle La Merced (Tramo entre la Calle Consuelo y 28 de Julio): La calle La Merced debió ser dividida en dos tramos para cuantificar su grado de afección por la contaminación: el primero que parte de la Plaza de Armas y termina en la Calle Consuelo y el segundo que parte de la Calle Consuelo y termina en la Calle 28 de Julio. El Primer Caso presenta un grado de contaminación mediano, al contabilizarse 897 vehículos en hora punta y al ser estos vehículos en su gran mayoría taxis y vehículos particulares, pero el segundo tramo resulta alarmante, registrándose un incremento de casi el doble de flujo que el primer tramo, es decir 1492 vehículos en hora punta, esto debido al aporte de vehículos desde la calle Tristán, por donde se desvían unidades del deficiente sistema de transporte público de la ciudad, compuesto por "Combis" “Custers" y Ómnibuses pequeños.

Vías Perimetrales a la Plaza de Armas: El grado de contaminación que se ha registrado en la denominada Plaza de Armas y en las vías perimetrales a los portales es alarmantemente, pues se ha convertido en nudo de confluencia de gran cantidad de vehículos particulares y de taxis que saturan estos espacios sobre todo en las denominadas "horas punta". Así se tiene: Vía perimetral al Portal de Flores: 1950 vehículos; Vía perimetral al Portal de San Agustín: 1356 vehículos; Vía perimetral al portal de la Municipalidad: 1560 vehículos en hora punta.

Calle Palacio Viejo (Tramo entre las Calles San Juan de Dios y Cruz Verde): El grado de contaminación registrado es alto, fue contabilizado un total de 1216 unidades vehiculares en hora punta.

Calle San Camilo/Consuelo (Tramo entre las calles San Juan de Dios y Cruz Verde): Dada la continuidad de uso que mantiene el Mercado de San Camilo que lo cualifica como uno de los 
principales centro de abasto de Arequipa Metropolitana y en vista del creciente incremento poblacional que ha experimentado la ciudad en las últimas décadas, la zona se encuentra afectada por diversos factores contaminantes que afectan directamente los valores patrimoniales de las edificaciones del sector, siendo la principal la cantidad de vehículos que pasan o convergen en este nodo urbano de la ciudad, además de la contaminación producida por los desechos orgánicos que la actividad en referencia produce.

Calle Cruz Verde / Villalba: El número de unidades móviles que circulan por esta vía en hora punta tienen un promedio de 636 y se enmarcaría en un grado de impacto mediano. El tipo y el modo de circulación hacen que el problema se agrave, y es que por esta calle circulan unidades de transporte público de las denominadas "Combis" y "Custers" además del tráfico de vehículos particulares y taxis.

Avenida Goyeneche: Actualmente la Avenida Goyeneche ysu prolongación denominada "Jorge Chavez", se ha convertido en una de las principales vías colectoras del deficiente transporte público de la ciudad, que lleva a los pasajeros del Suroeste al Noreste de la ciudad, teniendo un altísimo número de unidades vehiculares en hora punta, 1880, lo cual ha hecho que se convierta en uno de los lugares con índices de mayor grado de contaminación en Arequipa.

Las calles y vías mencionadas anteriormente fueron consideradas con un alto grado de contaminación vehicular y en ellas también fue realizado un diagnostico de las patologías observadas. En la tabla 2, son mostrados los números de monumentos arquitectónicos, así como, los inmuebles con valor patrimonial afectados.

Tabla 2. Inmuebles patrimoniales afectados por alto grado de contaminación vehicular

\begin{tabular}{|c|c|c|c|}
\hline Calles/Vías & $\begin{array}{l}\text { Monumentos } \\
\text { Arquitectónicos }\end{array}$ & $\begin{array}{l}\text { Inmuebles con } \\
\text { Valor } \\
\text { Patrimonial }\end{array}$ & Patologías Típicas Detectadas \\
\hline Calle Puente Grau & 13 & 6 & $\begin{array}{l}\text { Pátinas de enmugrecimiento y tinción/ } \\
\text { Exfoliación/Disgregación/Eflorescencias }\end{array}$ \\
\hline Calle La Merced & 34 & 6 & $\begin{array}{l}\text { Pátinas de enmugrecimiento y tinción/ } \\
\text { Exfoliación/Disgregación/Eflorescencias/Salini } \\
\text { zación }\end{array}$ \\
\hline $\begin{array}{l}\text { Vías Perimetrales a la } \\
\text { Plaza de Armas }\end{array}$ & 5 & 2 & $\begin{array}{l}\text { Pátinas de enmugrecimiento } \\
\text { tinción/Exfoliación }\end{array}$ \\
\hline Calle Palacio Viejo & 4 & 3 & $\begin{array}{l}\text { Pátinas de enmugrecimiento y tinción/ } \\
\text { Exfoliación/Eflorescencias/Salinización }\end{array}$ \\
\hline $\begin{array}{ll}\text { Calle } & \text { San } \\
\text { Camilo/Consuelo } & \end{array}$ & 1 & 3 & $\begin{array}{l}\text { Pátinas de enmugrecimiento } \\
\text { tinción/Exfoliación }\end{array}$ \\
\hline
\end{tabular}




\begin{tabular}{|c|c|c|c|}
\hline $\begin{array}{l}\text { Calle Cruz Verde / } \\
\text { Villalba }\end{array}$ & 7 & 6 & $\begin{array}{l}\text { Pátinas de enmugrecimiento } \\
\text { tinción/Disgregación/Exfoliación/ } \\
\text { Eflorescencias }\end{array}$ \\
\hline Avenida Goyeneche & 2 & 5 & $\begin{array}{l}\text { Pátinas de enmugrecimiento y tinción/ } \\
\text { Disgregación/Exfoliación/Eflorescencias/Salin } \\
\text { zación }\end{array}$ \\
\hline Total & 66 & 31 & $\begin{array}{l}\text { Pátinas de enmugrecimiento } \\
\text { tinción/Disgregación/Exfoliación/ } \\
\text { Eflorescencias/Salinización }\end{array}$ \\
\hline
\end{tabular}

A seguir son descritas las calles y vías afectadas por un grado medio de contaminación:

Calle Santa Catalina: Para nuestro estudio esta calle fue dividido en dos tramos: El primero entre las calles Ayacucho y Ugarte, en el que se observo una cantidad de 508 unidades móviles en hora punta y el segundo que va desde Ugarte a San Agustín, alcanzando 620 unidades en hora punta, en su mayoría el tipo de vehículos que circulan por la vía son carros particulares y en especial taxis "Tico".

Calle San Francisco: El grado de impacto de contaminación en esta calle está en el límite de convertirse de mediano a alto, pues se ha registrado un total de unidades móviles en hora punta de 960, dejando en riesgo los Monumentos históricos representativos tanto de la arquitectura civil, como pública de la ciudad.

Calle San Agustín: El grado de impacto en la Calle San Agustín es mediano con respecto al total de muestras en la ciudad, pero el problema reside en el tipo de vehículos que tocan tangencialmente la calle, se referi a los provenientes de la Calle Sucre y de la calle Villalba, que pertenecen al deficiente y contaminante sistema de transporte público de la ciudad.

Calle Puente Bolognesi: El grado de impacto de contaminación es intermediario con respecto a las demás calles de la ciudad, siendo todavía una vía muy importante que conecta el mismo centro de la ciudad ( Plaza de Armas) con la otra rivera del río Chili.

La Calle Zela ( Tramo entre las calles Jerusalén y Santa Catalina): Para este estudio ella fue dividida en dos tramos, el primero que va desde la calle Jerusalén hasta Santa Catalina, habiéndose contabilizado un total de 588 unidades móviles en hora punta, y el segundo desde la Calle Santa Catalina hasta Bolívar con un número muy inferior al tramo anterior.

Calle Ugarte (Tramo entre las calles Rivero y Santa Catalina): También fue dividida en dos tramos. El primer tramo ha sido situado entre las calles Rivero y Santa Catalina, y el segundo 
entre la calle Santa Catalina y Bolívar; siendo el primero el que más alto índice de contaminación presenta, alcanzando un promedio de 920 vehículos en hora punta.

Calle Álvarez Thomas: El tráfico vehicular es mediano entre los tramos de las calles Moran y Consuelo, habiéndose registrado un total de 756 unidades en hora punta, afectando a estas estructuras de alto valor patrimonial.

Las calles y vías mencionadas anteriormente fueron consideradas con un mediano grado de contaminación vehicular y en ellas también fue realizado un diagnostico de las patologías observadas. En la tabla 3, son mostrados los números de monumentos arquitectónicos, así como, los inmuebles afectados y sus respectivas patologías divididas por calles.

En este estudio también fueron identificadas dos calles con bajo grado de contaminación vehicular y son:

La Calle Zela, en la cuadra entre Santa Catalina y Bolívar, la cual además de contemplar un bajo índice de unidades móviles en hora punta (65) no cuenta con edificaciones de valor patrimonial para ser considerada dentro del presente trabajo.

La Calle Ugarte, en el tramo entre Santa Catalina y Bolívar, al igual que el tramo anterior no presenta un gran número de unidades móviles que pasan por ella (73) pero a diferencia de Zela si cuenta con monumentos históricos expresamente declarados.

Tabla 3. Inmuebles patrimoniales afectados por mediano grado de contaminación vehicular

\begin{tabular}{|c|c|c|c|}
\hline Calles/Vías & $\begin{array}{l}\text { Monumentos } \\
\text { Arquitectónicos }\end{array}$ & $\begin{array}{l}\text { Inmuebles con } \\
\text { Valor Patrimonial }\end{array}$ & Patologías Típicas Detectadas \\
\hline Calle Santa Catalina & 21 & 2 & $\begin{array}{l}\text { Pátinas de en mugrecimiento y tinción/ } \\
\text { Disgregación/Eflorescencias/Salinización }\end{array}$ \\
\hline Calle San Francisco & 17 & 4 & $\begin{array}{l}\text { Pátinas de enmugrecimiento y tinción/ } \\
\text { Disgregación/Eflorescencias }\end{array}$ \\
\hline Calle San Agustín & 4 & 3 & $\begin{array}{l}\text { Pátinas de enmugrecimiento y tinción/ } \\
\text { Disgregación/Eflorescencias }\end{array}$ \\
\hline $\begin{array}{l}\text { Calle } \\
\text { Bolognesi }\end{array}$ & 10 & 4 & $\begin{array}{l}\text { Pátinas de enmugrecimiento y tinción/ } \\
\text { Disgregación/Eflorescencias/Salinización }\end{array}$ \\
\hline Calle Zela & 3 & 3 & $\begin{array}{l}\text { Pátinas de enmugrecimiento y tinción/ } \\
\text { Disgregación/Eflorescencias }\end{array}$ \\
\hline Calle Ugarte & 4 & 3 & $\begin{array}{l}\text { Pátinas de enmugrecimiento y tinción/ } \\
\text { Disgregación/Exfoliación }\end{array}$ \\
\hline Calle Álvarez Thomas & 23 & 4 & $\begin{array}{l}\text { Pátinas de enmugrecimiento y tinción/ } \\
\text { Disgregación/Exfoliación }\end{array}$ \\
\hline Total & 82 & 23 & $\begin{array}{l}\text { Pátinas de enmugrecimiento y tinción/ } \\
\text { Disgregación/Exfoliación/Eflorescencias/Salinizació }\end{array}$ \\
\hline
\end{tabular}


En la Tabla 4 se observa un resumen del cuantitativo de vehículos en hora punta para todas las calles monitoreadas en este estudio. Aquí son observados desde valores de 65 hasta 1950 vehículos por hora punta, de esta forma queda claro la gran dispersión en lo que se refiere a grados de contaminación en las calles de Arequipa.

Tabla 4. Cantidad de vehículos que circulan en una "hora punta" en calles de alta concentración de monumentos históricos

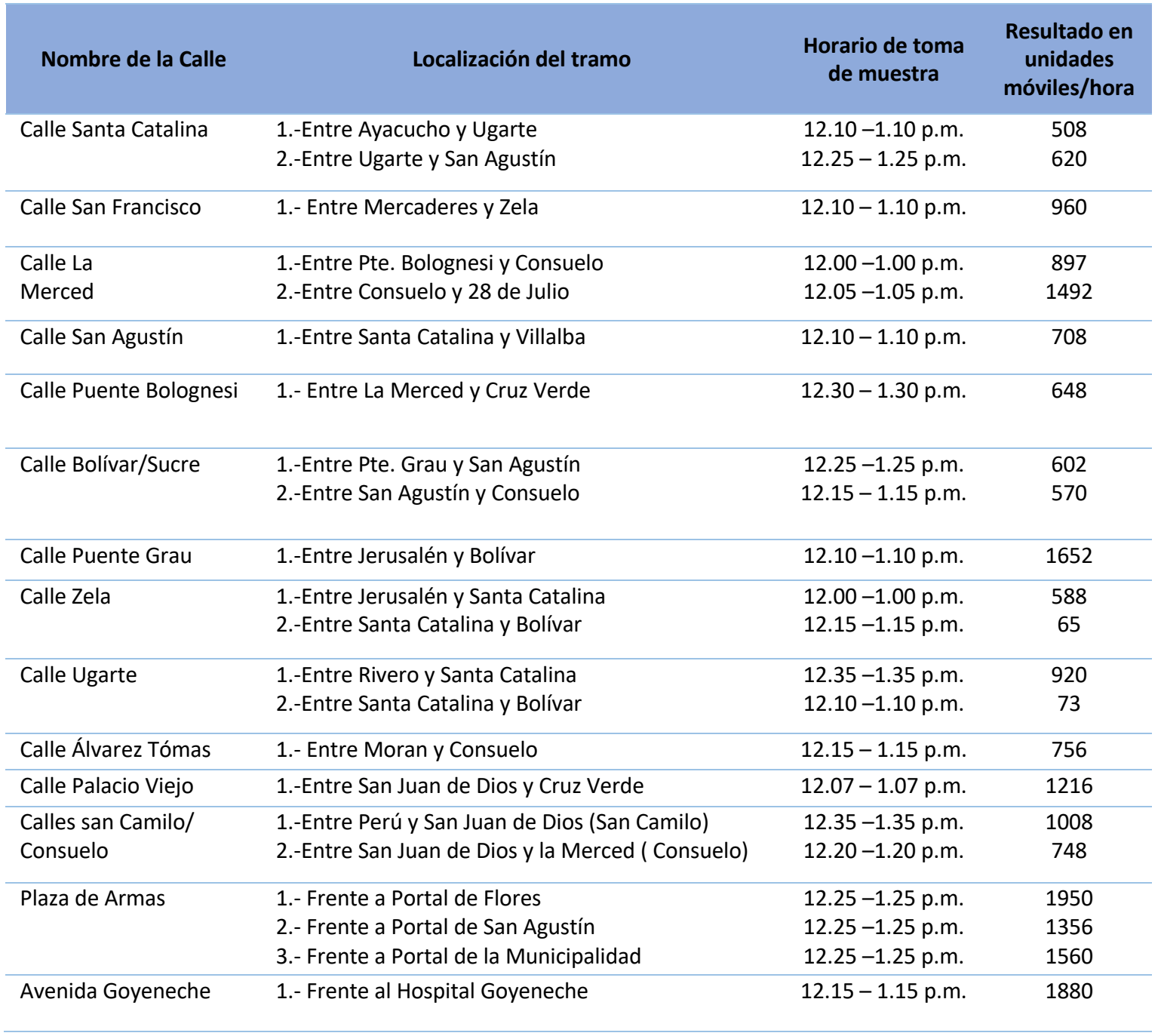

Al analizar las tablas 2 y 3 , se observa los tipos de patologías presentes en los monumentos arquitectónicos e inmueble históricos. Se ve que las patologías son redundantes en todas las calles y vías con alto e medio grado de contaminación la diferencia está en el número de edificios afectados. A seguir son descritas las patologías observadas y su asociación con el grado de contaminación: 
Enmugrecimiento y Tinción: es la Pátina de Enmugrecimiento o suciedad es comúnmente confundida con la pátina de envejecimiento, las cuales pueden coincidir en apariencia pero no en origen, esta se presenta mucho en la ciudad de Arequipa, sobretodo en edificaciones localizadas en zonas de alta contaminación vehicular conforme se observa en las Tablas 2 y 4.

Disgregación. Es el proceso de desintegración de los materiales su característica fundamental es que la disgregación se presenta de manera granular y los elementos se hacen literalmente "polvo". Este proceso se inicia en la superficie, con la pérdida de sus condiciones originales de manufactura, y de su "pátina"; y continúa gradualmente dependiendo de intensidad y frecuencia de los agentes contaminantes como también de la calidad de los materiales. La disgregación va asociada a los procesos de humidificación, capilaridad y salinización de las piezas.

En los monumentos de estudio se ha observado que esta patología afecta indistintamente a diferentes estructuras, estén ubicadas estas en la parte alta, media o base de los paramentos. En cuanto a los efectos de la contaminación vehicular en especifico, se ha observado que la disgregación es más severa a la altura de los tubos de escape de los vehículos; y su característica frecuente es en color negro de las superficies de los monumentos a esta altura.

El caso más representativo de esta patología ha sido observado en los paramentos exteriores del Hospital Goyeneche en la esquina de la calle Paucarpata con Goyeneche. En este caso el daño es severo, mas aun tratándose de "sillar rosado" que por su naturaleza es más compacto y de mayor dureza.

Exfoliación. Es un proceso similar a la disgregación su característica fundamental es la separación por "capas" o láminas de partes de los elementos. En las causas también intervienen los agentes térmicos y así mismo procesos de salinización que son los que originan el endurecimiento de la superficie y la separación de la misma. Esta patología se ve frecuente en los paramentos expuestos a la exposición solar.

Las observaciones muestran que los procesos de exfoliación son más frecuentes en las capas pictóricas y en los encalados, por la estructura misma de los materiales y dureza de los encalados. En los morteros sin embargo se encuentra rara vez esta patología.

Respecto a la contaminación producida por los vehículos, esta patología mantiene los patrones observados en la disgregación. 
Eflorescencias o neo formaciones. Es el proceso de formación de cuerpos sobre la superficie de los monumentos en área de diferentes tamaños. Este proceso está dado por la transformación de los elementos solubles propios del material de sillar que como consecuencia de agentes como el agua en sus diferentes formas de actuación, dan origen a la formación de nuevos cuerpos sólidos que se acumulan en la superficie.

Se ha observado que esta patología tiene relación con la acumulación de partículas sólidas producto de la contaminación vehicular, caracterizando a estas neoformaciones de color negro. Un ejemplo distintivo es el que se ha observado en un monumento de la calle Puente Grau.

Salinización. Es un proceso en el que intervienen elementos salinos ajenos a la composición misma de los materiales de sillar, principalmente sales orgánicas provenientes de la orina, que son depositadas sobre los monumentos como consecuencia de las malas costumbres de higiene de las personas y también por la presencia de animales. La acumulación de basura en los diferentes periodos de la historia de los monumentos también es el origen de esta patología. Este proceso es más activo en la presencia de agua, sea originada por capilaridad y/o por humedad. La característica fundamental de la salinización es que se forman eflorescencias o cristalizaciones de sales sobre la superficie y son generalmente blancas. Esta patología se distribuye principalmente en la parte inferior de los paramentos, algunas veces presente en diferentes alturas de los mismos. El daño surge cuando la cristalización de las sales se hace dentro de los elementos en su parte cercana a la superficie y sobre ella misma. La dilatación de los componentes salinos provoca la separación y ruptura de la estructura del sillar.

En el centro histórico se ha observado la presencia frecuente de esta patología. Respecto a su relación con el monóxido de carbono, se ha observado que esta patología se asocia a las áreas de escurrimiento de los sólidos acumulados que como consecuencia del periodo de lluvias son arrastrados y depositados en la superficie de las paredes de los monumentos.

Dos ejemplos resaltantes muestran los daños causados por este tipo de patología: el que se observa en el muro de la esquina del Portal de la Municipalidad con la calle La Merced, y en la parte inferior de la fachada del Monasterio de Santa Catalina. En este último caso se agrava por la falta de cuneta en la calzada que hace que el agua salte al muro durante el tránsito vehicular en los episodios de lluvia. 


\section{Consideraciones Finales}

A partir de este estudio es posible afirmar que la mayor parte de las patologías están asociadas a la contaminación ambiental y que el producto de esta contaminación está directamente relacionado con el tipo y la cantidad de vehículos que transitan las calles del centro histórico.

Fue posible dividir las calles del centro histórico monumental de Arequipa en tres grados de contaminación: alto, mediano y bajo grado de contaminación.

Se Puede afirmar que los daños en los monumentos del Centro Histórico de Arequipa, son la combinación de las diferentes patologías observadas, que afectan los siguientes aspectos.

En primer lugar transforman el carácter de su monumentalidad, la arquitectura arequipeña está caracterizada por su resonancia con el ambiente limpio y transparente en el que la luminosidad resalta los monumentos. Estos se ven sucios y han ennegrecido sus superficies. En segundo lugar atenta contra su originalidad pues muchos monumentos dañados por la contaminación, son restaurados sin idoneidad, y sin un diagnostico científico de las patologías que los afectan. Esto hace que se retire la superficie de los monumentos. A esto se suma la idea errónea pero común de que la "Ciudad Blanca" se debe al sillar, lo cual hace que se intente recuperar esta característica. Esta práctica generalizada hace que las superficies y pátinas originales de los monumentos se pierdan irremediablemente. El resultado es una antigua ciudad con la superficie nueva de sus monumentos.

En tercer lugar atenta con la conservación del centro histórico. Las patologías originan daños irreversibles y la pérdida de elementos de la estructura de los monumentos. Esta pérdida afecta en varios casos a la estructura misma en su conjunto. Este aspecto exige inmediatas acciones de conservación para frenar los daños, y la implementación de políticas adecuadas para prevenirlos y/o atenuar su gravedad.

Los daños más importantes en los monumentos del Centro Histórico de Arequipa, como consecuencia de la contaminación ambiental son: Perdida de la superficie original de los monumentos, destrucción de elementos de sillar en los monumentos, cambio en la coloración y acumulación irreversible de materiales nocivos en las superficies.

A partir de este estudio se puede sugerir acciones como un reordenamiento del transporte vehicular en la ciudad, más rigor para otorgar las licencias de funcionamiento de los vehículos 
y finalmente la concientización de los moradores de la ciudad al respecto de esta problemática.

\section{Referencias}

ALCALDE, M., VILLEGAS, R., VALE, J. F., MARTíN. 1990. Diagnosis y tratamiento de la piedra. CSIC/ICCET, Monografía no 400. Madrid.

ALONZO, E.; MARTINEZ, L. 2003. The role of environmental sulphuron degradation of ignimbrites of the Cathedral in Morelia, Mexico. Building and Environment, 38 pp, 861-867.

BRANDI, C. 1977. Teoria del Restauro. Roma: Einaudi.

CABRERA GARRIDO, J. M. 1979. Causas de alteración y métodos de conservación aplicables a los monumentos hechos con piedra. Materiales de Construcción, 174: 5-42.

CONAM, 2006. Plan A Limpiar el Aire - Gesta Zonal de Aire Arequipa, Fondo Editorial del CONAM.

DEL MONTE, M. 1990. Microbioerosion and biodeposits on stone monuments: pitting and calcium oxalate patinas. Advanced Workshop, Analytical Methodologies for the Investigation of Damaged Stones. Pavia. $29 \mathrm{p}$.

DIGESA. 2015. Inventario de Emisiones Cuenca Atmosférica de la Ciudad de Arequipa, consultado en: http://www.digesa.minsa.gob.pe/depa/inventario_aire/fuentes_fijas/Informe\%20Inventario\%20Integra do\%20Arequipa.pdf

GARLAN, J. A. 1978. Dry and wet removal of sulfurs from atmosphere. Atmosphere Environment, 12. pp 957-968.

GONZALES, S. y HUARACHI, A. 2000. Propiedades Físicas, Mecánicas y Químicas del sillar de Arequipa y su tratamiento para evitar su proceso de envejecimiento, Arequipa, Universidad Nacional de San Agustín.

GONZALES, Z. J. M. 2014. Informe de investigación: Salud ocupacional en las canteras de sillar, distritos de Yura y Cerro Colorado, Arequipa-2014, Universidad Ciencias de la Salud.

HELENE, P. R. L. 1992. Manual para reparo, reforço e proteção de estruturas de concreto. 2da Edição, São Paulo: Pini Ltda.

INC, INSTITUTO NACIONAL DE CULTURA. 1999. Relación de Monumentos históricos del Perú. 97 p.

ISAIAS, G. C. 2011. Concreto: Ciência e Tecnologia. 1a ed. IBRACON, v. 2. - Instituto Brasileiro do Concreto - São Paulo: Geraldo Cechella Isaias.

MORALES, A. J. (1996), El patrimonio Histórico-Artístico. Historia 16. Madrid, 155 p.

MUNICIPALIDAD DE AREQUIPA. 1999. Proposal to UNESCO to declare the historical centre of Arequipa a cultural heritege, consultado en https://whc.unesco.org/en/list/1016/ 
MUNICIPALIDAD PROVINCIAL DE AREQUIPA. 2017. Plan maestro del centro histórico de Arequipa y zona de amortiguamiento PLAMCHA 2017-2027.

NEIRA, A.; RODRIGUEZ, G. M. G.; MEDINA, M.A. M. PAZ SOLDAN, E. Q.; MUNHOZ, C. J. G. 1990. Historia General de Arequipa. Fundación M. J. Bustamante de la Fuente.

PETRUCCI, E. 1972. Patologia das Estruturas: Um desafio a engenheria. Rio de Janeiro, Anais Rio de Janeiro: Clube de Engenharia.

PRADA, J. L.; VALENCIANO, A.; NAVARRO, A. 1995. Procesos de alteración de materiales pétreos en edificios de interés histórico, Acta geológica hispánica, v 30, 97 p.

PRADA, J. L. 1995. Caracterización de formas y procesos de alteración, observadas en piedra de construcción de edad miocénica del área monumental romana de Tarragona. Tesis doctoral. Universidad de Barcelona. 284 p.

RAMON, G. 1992. Evolución Histórica Urbana de Arequipa. Lima: Epígrafe Editores.

RODRIGUEZ, V. 2004. Manual de patología de la edificación, Departamento de Tecnología de la Edificación (e.u.a.t.m.) Universidad Politecnica de la Edificação, Madrid, 2004.

SENAMHI. Datos Hidrometeorológicos en Arequipa. Disponible en https://www.senamhi.gob.pe/main.php?dp=arequipa\&p=estaciones

URUCHURTU J., Efectos de la contaminación en edificios del patrimonio histórico, Inventio, Vol 4, Nro 7, (2008) p 51.

VASSILAKO, C. y SALTA, A., 1993, Synergistic effects of $\mathrm{SO}_{2}$ and $\mathrm{NO}_{2}$ in their action on marbles studied by reversed flow gas chromatography. Conservation of Stones and other Materials, 21th International RILEM/UNESCO Congress, Vol 1, pp 99-106.

WILLIAM, F. J. y GOLDICH, S. 1956. Rhyolitic Tuff Flows in Southern Peru. The Journal of Geology, Vol 64, Nro. 2 (Mar., 1956): 156-172. 